\title{
The Economy and Monetary Actions at Midyear: Review and Prospects
}

T HE COUNCIL of Economic Advisers (CEA), in their Annual Report of last January, projected a rapid advance in GNP for 1972. Real product growth was expected to be strong, and the rate of inflation was projected to decline significantly by the end of the year. This article examines the CEA's projections for 1972 in light of economic developments in the first two quarters. The factors relevant to an assessment of economic prospects in 1973 are also discussed.

\section{Recent Economic Developments}

Total spending (GNP) has advanced rapidly since late 1971, largely in response to stimulative monetary and fiscal actions in 1971. Growth in the money stock has been uneven for the last 6 quarters, but has averaged a 6.6 percent annual rate since early 1971 . In comparison, money increased at a 4.5 percent rate from early 1969 to early 1971. Fiscal actions have also been expansionary, with Federal expenditures rising at a 12.6 percent rate since first quarter 1971 , substantially faster than the 6.8 percent rate of increase in the previous two years.

A significant portion of the recent advance in GNP has been manifested in real product growth, with the associated rate of price inflation being moderate. Real product growth accelerated to a 7.5 percent annual rate from third quarter 1971 to second quarter 1972, more than triple the 2.2 percent increase in the previous year. The rate of inflation, as measured by the GNP price deflator, rose at a 2.8 percent rate from mid-1971 to second quarter 1972, compared to a 4.9 percent increase in the preceding year.

The rapid rise of real product has fostered a strong advance in employment. Payroll employment has increased at a 3.4 percent anmual rate since last fall, compared to a 1.1 percent rise in the previous year

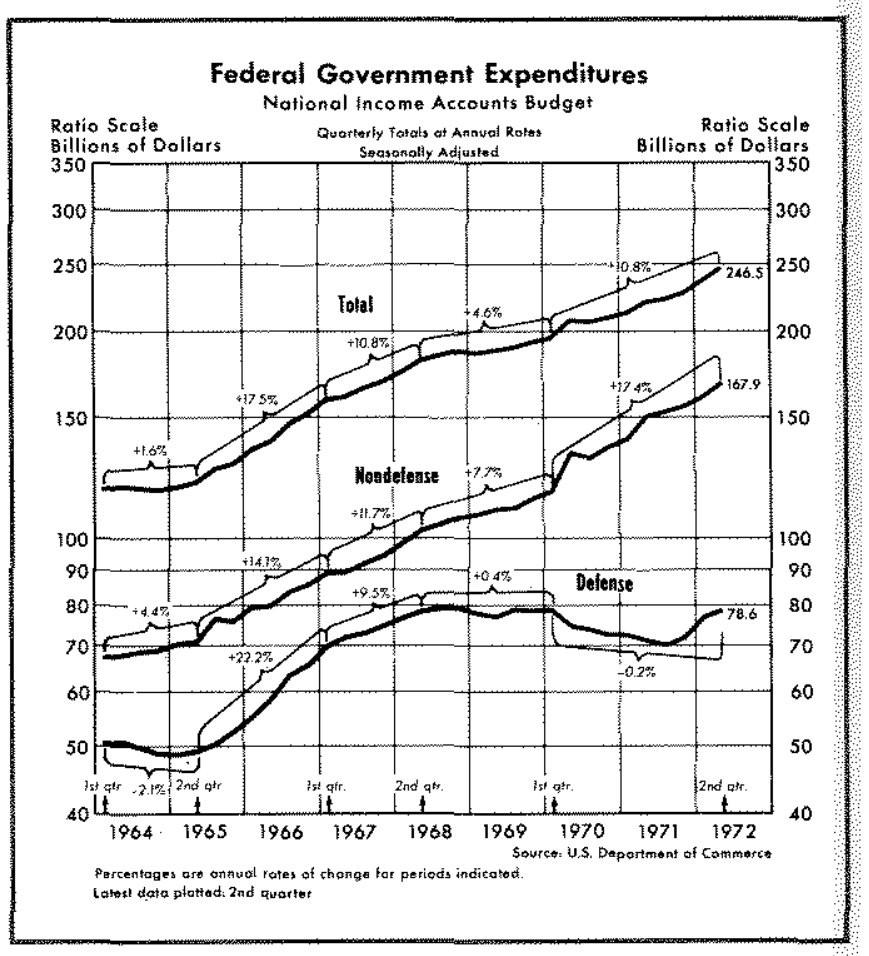

and a trend rate of growth of 2.1 percent from 1957 to 1971. The relative strength of these employment gains is noteworthy since the population of working force age is estimated to be growing at about a 1.7 percent annual rate. Total employment in July was 64.3 percent of the population of labor force age, the highest proportion in more than two years.

\section{CEA Projection for 1972}

The Council of Economic Advisers projected an increase in GNP from 1971 to 1972 of 9.5 percent, or 10.8 percent when translated into an increase for the year ending fourth quarter 1972. The advance in GNP from 1971 to 1972 was projected to consist of a 3 to

Page 2 


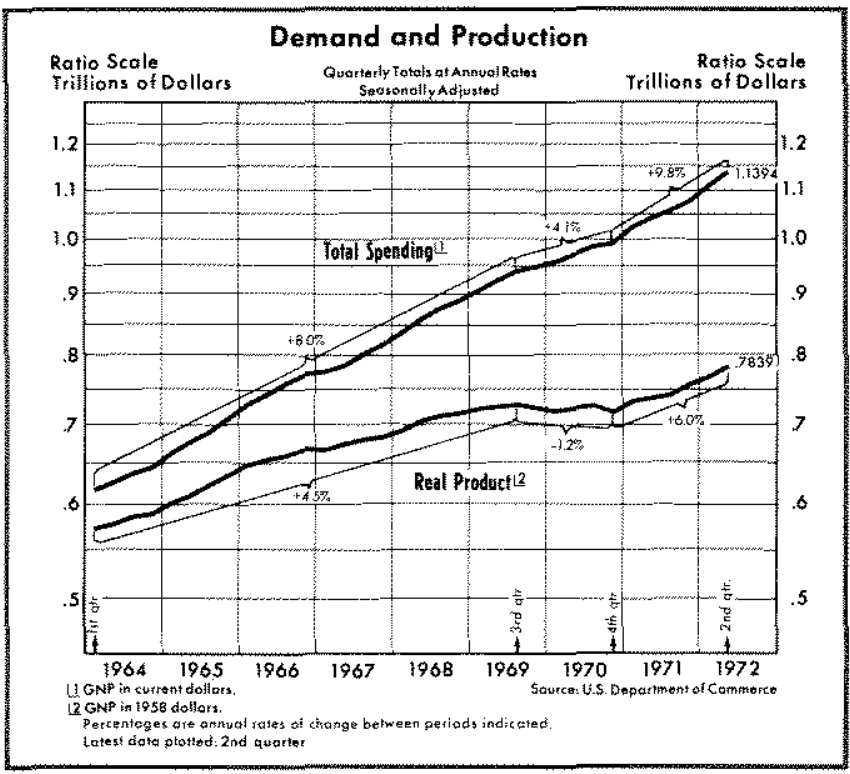

3.5 percent increase in prices and about a 6 percent rise in real product. The rapid advance in real product was expected to yield an unemployment rate of about 5 percent by the end of 1972 .

Given developments through the second quarter, the accompanying table shows the magnitudes in the second half of the year which would be consistent with the Administration's goals. Substantial progress was made in the first half of the year toward realizing the CEA goals for the year 1972. Moderated growth of both GNP and real product in the final six months of the year, and continuation of price increases at about the average rate of the past two quarters would be consistent with attainment of the CEA goals.

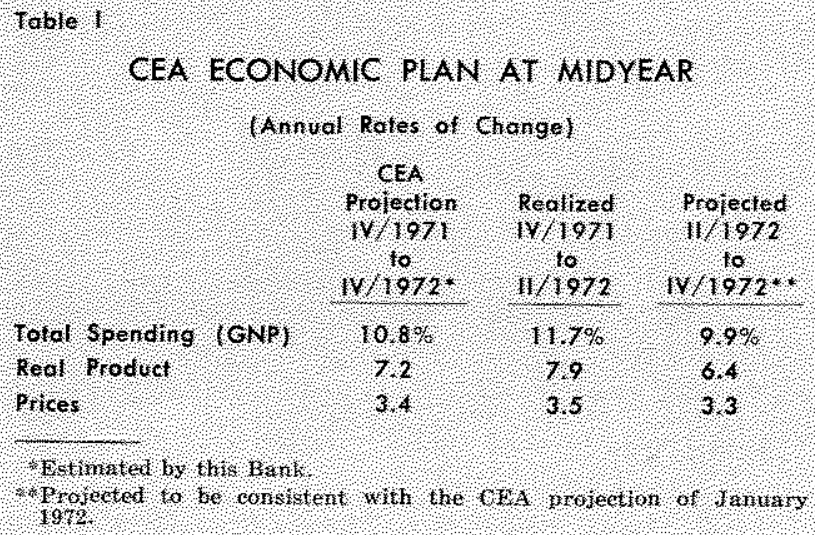

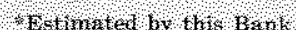

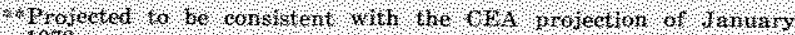
1972

Assumptions about the course of monetary actions in 1972 were not made explicit in the January CEA Report, but a 6 to 8 percent rate of money growth may have been considered an acceptable range at that time. Monetary actions, as measured by growth of the money stock, have averaged within this range

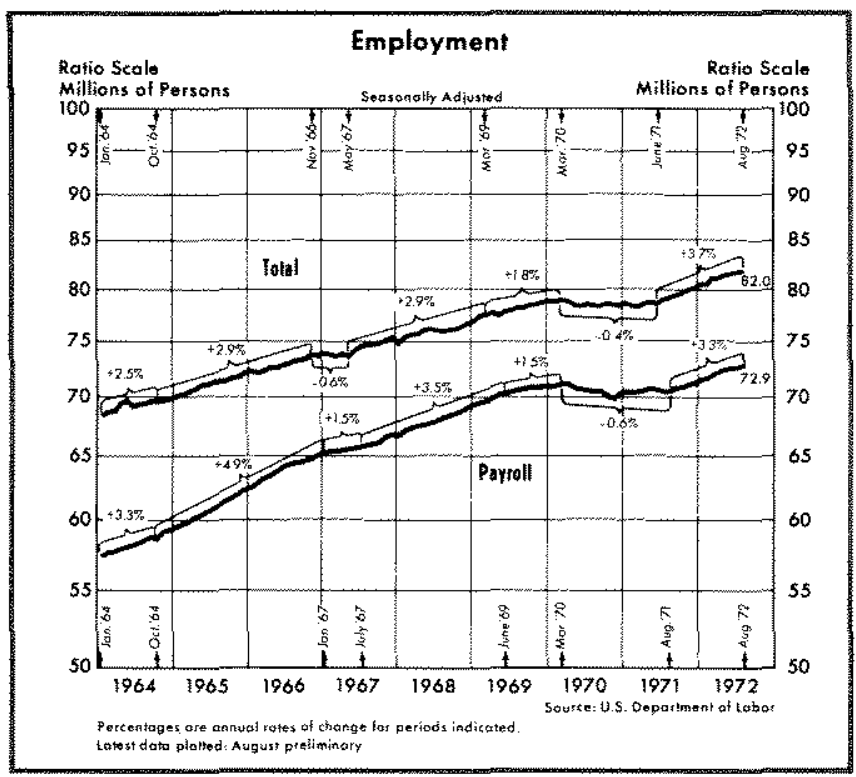

since late 1971, with money increasing at a 7 percent annual rate from fourth quarter 1971 to second quarter 1972 ( see chart on p. 4). Given the assumption of 6 to 8 percent money growth, the CEA's projections of GNP implied an increase in the velocity of money (the ratio of GNP to the money stock) from fourth quarter 1971 to fourth quarter 1972 of between 4.5 and 2.6 percent.

The velocity of money increased at a 4.4 percent annual rate from fourth quarter 1971 to second quarter 1972 , compared to a 1.4 percent average rate in the previous three years. Given an increase in money at a 6 percent rate from second to fourth quarter 1972 , growth of total spending consistent with the administration's target would imply growth of velocity at a 3.7 percent rate in the second half of the year. This velocity projection translates into a 4 percent increase for the four-quarter period ending late this year. An increase of 4 percent would represent the most rapid advance of velocity for a four-quarter period since 1966.

\section{Outlook for 1973}

The influence of monetary and fiscal actions on economic activity is largely determined for the rest of 1972 due to the usual delayed response of the economy to aggregative stabilization policy actions taken earlier. To say that such infuence is "determined" is not to say that it is known with certainty. Even knowing the path of monetary and fiscal actions up to the present does not mean that the impact of these actions can be assessed with great accuracy. Despite this uncertainty about the remainder of 1972 , but because of the lag in 


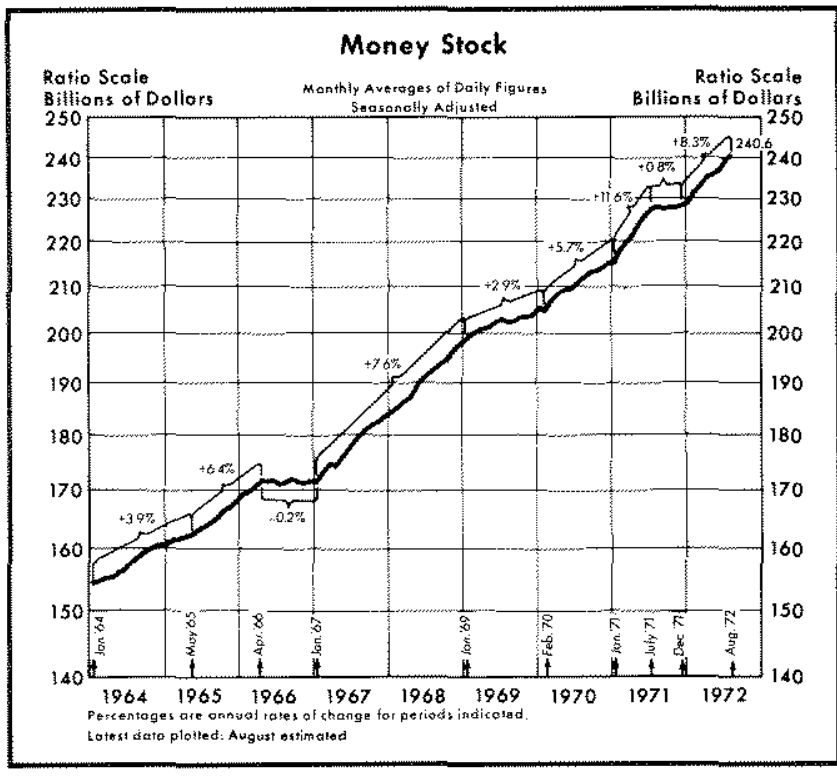

the effects of monetary and fiscal actions, such actions should be designed with an eye toward achievement of economic goals in 1973. Consequently, assessing economic prospects in 1973 takes more the form of a set of goals rather than a forecast. The chief questions to be asked presently concern the feasibility and desirability of such goals.

Some alternative target paths for the economy in 1973 are discussed below. These paths are stated in terms of movements of total spending, prices, and output. These alternative target paths are examined in terms of their feasibility and their implications for monetary growth. The velocity of money is also considered in the examination of these alternatives.

Continued rapid real growth in 1973 - First, consider the possibility of sustaining nominal and real growth at rates that appear to be prevailing in 1972 . Continuation of GNP growth within the 9 to 11 percent range through 1973 would represent the highest growth rate for any successive two-year period since 1950-52.

Leaving aside for a moment the means of sustaining this very rapid growth in GNP, what might be the implications for real growth and prices if this rapid increase in GNP were realized? Real product growth of 5 to 7 percent through 1973 would represent the longest period of such sustained rapid growth since the large build-up phase of the Vietnam War in 1964-66. Current rapid real growth has been possible because of the substantial slack that exists in the economy as a result of the slowdown in economic activity from late 1969 to mid-1971.
Strong real output growth is consistent with a steady lowering of the unemployment rate. However, if real output growth beyond a 4 to 5 percent rate is still sought after full employment is approached, inflationary pressures could reappear. Since there is sub. stantial uncertainty concerning the lags between monetary and fiscal actions and real output, considerable care must be exercised to avoid over-stimulat. ing the economy as it approaches full employment.

Slowing of nominal and real growth in $1973-$ An alternative path would be one of slowing from the rapid 9 to 11 percent nominal growth and the 5 to 7 percent real growth. If it is decided that nominal and real growth should be slowed in 1973, implying more attention to the avoidance of possible inflationary pres. sures and less attention to promoting high real output growth, what course of monetary actions would be consistent with those objectives?

On the assumption that a 7 percent growth path of GNP for 1973 is deemed consistent with continued slowing of price inflation, and yet is consistent with real growth in the 4 to 5 percent range, it is necessary to consider assumptions about the growth of money and the velocity of circulation. A 7 percent growth path for GNP, when considered along with a slowing in the velocity of money to a 2 percent rate from the recent accelerated rate of about 4 percent, implies monetary growth of 5 percent.

Alternatively, given a 7 percent GNP target, if velocity is assumed to grow faster than 2 percent, required money growth would then be less than 5 percent. Clearly, once goals for GNP are selected, some information has to be brought to bear on the most reasonable assumption about the course of money velocity before a path of monetary growth can be chosen.

\section{Velocity Considerations}

Any assessment of the appropriate course for monetary policy in coming quarters requires some assump tions about the future trend of velocity. As illustrated in the accompanying chart, the direction of velocity movements over the business cycle is quite predictable, tending to slow before and during recessions, then accelerate sharply in the early stages of recovery. In the latter stages of recovery, velocity slows somewhat relative to its movement in the early stages. Less predictable, however, are the apparent changes in the trend growth of velocity. Secular trends in velocity are usually considered to be the result of institutional and technical factors relating to the structure of the economic and financial system, and by definition tend to change slowly over time. 


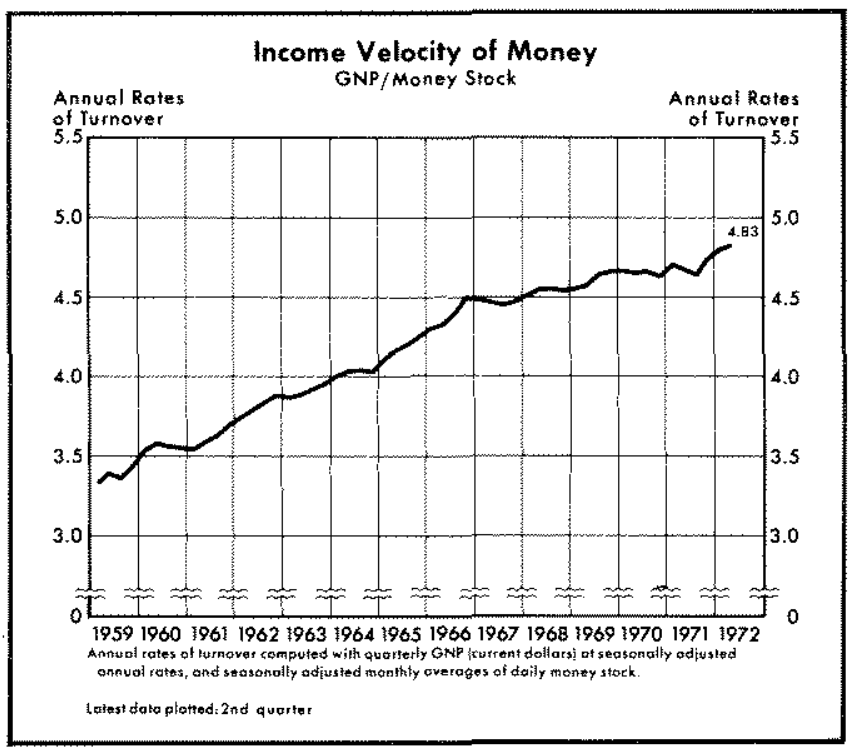

Designing the course of monetary policy in coming quarters requires a determination of whether or not the recent acceleration of velocity is cyclical or is indicative of a change in trend. At this time, little firm evidence is available to make a strong case for either altemative. If the recent acceleration of velocity proves transitory, and velocity returns to about the 1 to 2 percent trend rate of 1966 to 1970 , monetary growth of 5 to 6 percent would be consistent with a 7 percent advance in GNP for 1973. On the other hand, if velocity resumes its $1953-66$ trend rate of about 3.5 percent, required growth of the money stock would be only about 3.5 percent.

\section{Conclusion}

The economy has surged forward thus far in 1972, and preliminary indications are that this momentum will carry through the remainder of the year. It now appears very likely that the CEA plan for 1972 will be realized. Achievement of the CEA's 1972 goals is possible even with some slowing in GNP and real product growth in the second half of the year.

At this time, it is necessary for stabilization authorities to determine a course of action with an eye toward economic goals in 1973 and beyond. Continued real growth at 1972 rates would be accompanied by continued employment gains, but this course must be viewed in light of the inflationary pressures which could emerge as the economy nears the full employment level of activity.

A path of slower growth in GNP would more likely be consistent with the avoidance of renewed inflationary pressure. Monetary actions consistent with the achievement of this somewhat slower growth requires some assessment of the most likely course for the velocity of money. A desire for slower growth in GNP, and an assumption of continued growth in velocity at the 3.5 to 4 percent rate of recent quarters, would imply required monetary growth of about 3.5 percent. A slowdown of velocity growth, on the other hand, would imply required monetary expansion of about 5 to 6 percent, if a 7 percent GNP goal was sought.

The experience of the early recovery periods following a number of postwar recessions suggests velocity increases in excess of 3 percent for a sustained period can occur under current economic conditions. If this is the case, a slower rate of money growth than the 7 percent experienced over the past few quarters could be accompanied by progress toward both full employment and price stability. The more rapid the increases in velocity, the more monetary growth could be moderated to achieve these goals.

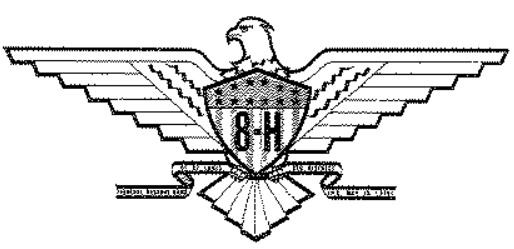

